\title{
The Relationship of The Marketing Mix to Customer Loyalty in DetailBOX Autodetailing Center
}

\section{Muhammad Rifki' Mazaya²}

\section{INSTITUTION}

Program Studi Ilmu Komunikasi,

STIKOM Interstudi,

Indonesia

\section{PHONE}

EMAIL

${ }^{1}$ muhammadrifki1223@gmail.com 2mazayarizy95@gmail.com

\section{DOI}

https://www.doi.org/

10.37010/prop.v2i1.586

\section{PAPER PAGE}

$110-120$

PROPAGANDA is a Journal of Communication Studies which is publish twice a year on January and July. PROPAGANDA is a scientific publication media in the form of conceptual paper and field research related to communication studies. It is hoped that PROPAGANDA can become a media for academics and researchers to publish their scientific work and become a reference source for the development of science and knowledge.

\author{
Hubungan Bauran Pemasaran terhadap Loyalitas \\ Pelanggan di Perusahaan DetailBOX Autodetailing \\ Center
}

\begin{abstract}
Di dalam komunikasi bisnis ada banyak sekali alat dalam melakukan pemasaran, salah satunya adalah bauran pemasaran. Tujuan dari penelitian ini adalah untuk mengetahui hubungan bauran pemasaran (marketing mix) terhadap loyalitas pelanggan (customer loyalty) di perusahaan DetailBOX Autodetailing Center. Semakin meningkatnya pola hidup masyarakat Indonesia yang menggunakan mobil dan motor sebagai alat transportasi dalam kehidupan sehari-harinya, serta didukung angka penjualan kendaraan yang naik setiap tahunnya, maka dari itu masyarakat membutuhkan sebuah jasa untuk perawatan kendaraannya tersebut. Responden yang terlibat dalam penelitian ini adalah pelanggan dari DetailBOX yang diambil sebanyak 125 responden. Dengan memenuhi kriteria sampel responden adalah pelanggan yang sudah menggunakan jasa DetailBOX secara terus-menerus. Teknik dalam pengambilan sampel menggunakan non-probability sampling dengan metode teknik sampel Convenience Sampling. Dan data kemudian diolah menggunakan program SPSS version 25. Hasil dari penelitian ini menunjukkan bahwa bauran pemasaran (marketing mix) tidak memiliki hubungan yang kuat dengan loyalitas pelanggan (customer loyalty) karena terbukti dari hasil nilai analisis Pearson Correlation X dan Y yaitu memiliki nilai .134. Akan tetapi beberapa dimensi bauran pemasaran memiliki hubungan dengan loyalitas pelanggan, dikarenakan dari beberapa dimensi memiliki nilai sig. di bawah o,05 terdiri dari dimensi produk, tempat, orang dan bukti fisik, yang terbukti secara nilai individual terhadap loyalitas pelanggan di Perusahaan DetailBOX Autodetailing Center.
\end{abstract}

In business communication there are many tools in doing marketing, one of which is the Marketing Mix. The purpose of this study was to determine the relationship between the Marketing Mix and Customer Loyalty in the DetailBOX Autodetailing Center company. The increasing lifestyle of the Indonesian people who use cars and motorbikes as a means of transportation in their daily lives, and supported by the increasing number of vehicle sales every year, therefore people need a service for the maintenance of their vehicles. Respondents involved in this study were customers from DetailBOX which were taken as many as 125 respondents. By meeting the criteria for the sample, the respondents are customers who have used DetailBOX services continuously. The sampling technique used is non-probability sampling with the Convenience Sampling technique method. And the data is then processed using the SPSS version 25 program. The results of this study indicate that the Marketing Mix does not have a strong relationship with Customer Loyalty because it is evident from the results of the Pearson Correlation $X$ and $Y$ analysis that has a value of .134 . However, several dimensions of the Marketing Mix have a relationship with Customer Loyalty, because several dimensions have a sig value. below 0.05 consists of dimensions of product, place, person and physical evidence, which are individually proven value for Customer Loyalty at the DetailBOX Autodetailing Center Company.

\section{KEYWORD}

marketing mix, customer loyalty, automotive, DetailBOX Autodetailing Center

bauran pemasaran, loyalitas pelanggan, otomotif, DetailBOX Autodetailing Center 


\section{PENDAHULUAN}

Seiring perkembangan zaman, bisnis dalam bidang jasa di Indonesia selalu mengalami peningkatan. Banyak sekali pengusaha baru yang mulai menjalani bisnis dalam bidang jasa dengan melihat peluang di sekitar bahwa banyaknya permintaan akan jasa yang dibutuhkan masyarakat. Bisnis dalam bidang jasa juga sangatlah beragam, mulai dari pengiriman barang, penginapan, biro jasa tiket/wisata, percetakan, rental mobil ,hingga sampai pencucian kendaraan (carwash) serta perawatan body kendaraan (auto detailing).

Di tahun 2020 ini, bisnis yang sedang mengalami peningkatan terletak pada bisnis carwash dan auto detailing, bisnis ini berkembang pesat karena didukung dari data pengguna mobil dan motor pribadi yang setiap tahunnya terus meningkat hingga 1 juta unit, (Rahadiansyah, 2020). Bisnis ini pun juga menjadi peluang yang sangat besar terutama di DKI Jakarta kalau melihat dari beberapa data jumlah kendaraan yang terus naik di DKI Jakarta, (Widowati, 2019). Maka dari itu pemilik kendaraan membutuhkan sebuah jasa perawatan kendaraan untuk mobilnya tersebut.

Strategi dalam memasarkan bisnis dalam bidang jasa terletak pada kualitas dan pelayanan yang diberikan dari perusahaan itu sendiri, jika hal tersebut dapat terpenuhi oleh pelanggan maka akan otomatis menciptakan loyalitas atau kesetiaan terhadap perusahaan itu. Zeitaml dan Bitner (dalam Hurriyati, 2010) memberikan konsep bauran pemasaran tradisional yang terdiri dari 4P, meliputi produk, harga, tempat dan promosi. Sementara dalam layanan pemasaran, bauran pemasaran diperluas dengan menambahkan elemen bauran pemasaran non tradisional, yaitu orang, bukti fisik, dan proses sehingga mereka menjadi 7 elemen (7P). Jika ke-7 elemen di atas dapat terpenuhi dengan apa yang di inginkan oleh pelanggan, maka menjadikan sebuah perusahaan tersebut dapat yang utama di dalam benak pelanggan, sehingga pelanggan akan loyal menggunakan jasa perusahaan itu. Setelah menggunakan kombinasi terbaik dari strategi 7P, perusahaan yang bergerak dalam bisnis layanan diyakini dapat mempengaruhi pelanggan untuk melakukan pembelian secara terus-menerus dan menjadikan pelanggan setia terhadap perusahaan (Khan, S. M., \& Mahmood, 2014).

Seperti yang dikemukakan oleh (Hurriyati, 2010) kesetiaan pelanggan ialah sebagai komitmen terhadap pelanggan tetap dalam berlangganan ulang atau pembelian produk secara berulang dan layanan di masa mendatang, walaupun adanya pengaruh situasi pemasaran dan berakibat memiliki potensi untuk menyebabkan perubahan perilaku pelanggan. Maka dari itu, DetailBOX selalu tetap ingin berinovasi dan terus melakukan segala cara termasuk dalam hal promosi yang sebelumnya masih terdapat kekurangan, oleh karena itu promosi lebih di tingkatkan lagi seperti melakukan kegiatan promosi dengan menggunakan influencer otomotif atau artis- artis yang ada di Indonesia melalui media sosial dan juga memberikan potongan harga serta menyediakan paket detailing di dalam promosinya. Agar ke depannya dari hal tersebut nama DetailBOX semakin dikenal lagi secara luas, dan juga selalu meningkatkan kinerja pengerjaannya yang akan berdampak pada puasnya pelanggan terhadap jasa yang telah diberikan sehingga pelanggan akan loyal atau setia terhadap jasa DetailBOX ini. Loyalitas otomatis akan terbentuk dari rasa yang muncul dengan sendirinya di dalam setiap hati pelanggan, disebabkan oleh rasa puasnya terhadap produk atau pelayanan jasa yang diberikan, sehingga konsumen nantinya mau berlangganan dan akan terus-menerus menggunakan jasa itu walaupun ada beberapa pesaing yang menjalankan bisnis jasa semacam itu.

DetailBOX Autodetailing Center adalah perusahaan yang bergerak dalam bidang jasa perawatan kendaraan, pertama kali diperkenalkan sebagai salah satu salon pamungkas resmi Meguiar® pada tahun 2015 oleh penggila mobil yang memiliki perhatian. Terletak di tengah Jakarta Selatan, DetailBOX dibangun untuk semua penggemar otomotif untuk bertemu dan berbagi gairah yang sama, khususnya ketika datang untuk membersihkan, menyinari, dan mendetail. Proses dalam pengerjaannya dicapai dengan menghilangkan kontaminan yang 


\section{PROPAGANDA}

terlihat dan tidak terlihat dari bagian dalam kendaraan, dan memoles bagian luarnya menjadi hasil akhir bebas noda yang asli. Terdapat beberapa jenis perawatan kendaraan mobil seperti ceramic coating paint protection, comprehensive detailing, multistage paint correction, premium wash dan masih banyak lagi. DetailBOX juga menjual beberapa produk untuk perawatan bagian dalam dan luar kendaraan di antaranya, Meguiar's, GYEON, CarPro C.QUARTZ, Beeds, Menzerna dan masih banyak lainnya. Walaupun baru berjalan 5 tahun, tetapi DetailBOX sudah mampu menjadi yang nomor satu dalam industri autodetailing, di bawah PT Detailbox Indo Persada (DetailBOX, 2015).

Berdasarkan latar belakang tersebut di atas maka rumusan masalah adalah seberapa besar hubungan bauran pemasaran dengan loyalitas pelanggan di perusahaan DetailBOX. Adapun tujuan penelitian yang dapat dikemukakan adalah dari 7 dimensi bauran pemasaran, dimensi apakah yang paling berhubungan dengan loyalitas pelanggan di perusahaan DetailBOX.

\section{Bauran Pemasaran (Marketing Mix)}

Dalam penelitian yang dilakukan Ibomendel (2008) bahwa praktik pemasaran dan dampaknya terhadap loyalitas pelanggan di Perusahaan Telekomunikasi Palestina (Paltel) menunjukkan dampak signifikan dari instrumen yang membentuk hubungan bauran pemasaran (khususnya, produk / layanan, harga, promosi, dan penempatan / distribusi) pada loyalitas pelanggan. Dan juga Owomoyela et al. (2013) menyelidiki, secara empiris, dampak elemen bauran pemasaran terhadap loyalitas pelanggan pada pabrik Nigeria dan menemukan bahwa $4 \mathrm{P}$ asli memiliki hubungan dan efek yang kuat pada loyalitas konsumen. Maka bisa dikatakan bahwa dari 2 penelitian tersebut, dari hubungan bauran pemasaran dapat terbentuknya loyalitas antar pelanggannya.

Dalam buku Manajemen Pemasaran (Daryanto, 2011) Bauran pemasaran adalah segenap alat dalam melakukan pemasaran yang bersifat taktis, di mana perusahaan dapat mengendalikan tanggapan terhadap apa yang di inginkan oleh pasar penjualan. Dengan kata lain, dari adanya beberapa alat pemasaran taktis tersebut, suatu perusahaan dengan begitu memiliki cara untuk pengendalian segala aspek yang terkait pemasaran akan produk atau jasa nya, agar sesuai dengan yang di inginkan pada pasar penjualan di luar sana.

Menurut Othman \& Harun (2018) dengan mengadakan praktik bauran pemasaran suatu organisasi mencapai tujuannya melalui proses penjualan dan keuntungan yang mereka dapatkan. Hal ini dapat dicapai melalui beberapa variabel 7P yang meliputi product, place, price, promotion, process, people dan physical evidence. Dengan ini, yang jelas dengan memahami elemen-elemen yang ada di bauran pemasaran, dapat menjadikan acuan bagi pelaku bisnis untuk mempengaruhi pelanggan serta terus melakukan proses penjualan yang mampu memberikan keuntungan bagi kedua belah pihak.

\section{Product}

Produk adalah sesuatu barang yang diciptakan untuk ditawarkan kepada pasar agar nantinya mendapatkan sebuah pengakuan untuk dapat digunakan serta dikonsumsi, yang bisa menimbulkan perhatian karena menyebabkan efek kepuasan dan memenuhi kebutuhan, keinginan pelanggannya (Kotler, 2011). Produk di sini berarti segala hal yang dibuat atau diproduksi oleh perusahaan yang nantinya di jual ke pasar/konsumen, dan dari produk itu sendiri bisa untuk di konsumsi atau digunakan dalam memenuhi kebutuhan serta keinginan kehidupan sehari-harinya.

\section{Price}

Harga adalah nominal yang harus ditukar oleh konsumen agar mendapatkan sebuah penawaran (Friesner, 2014). Harga dalam hal ini, sebuah nominal uang yang harus dibayar oleh 
pelanggan kepada penjual/produsen dengan penawaran baik produk maupun jasa yang ditawarkan oleh penjual sesuai dengan jenis produk/jasa itu sendiri.

\section{Place}

Tempat menurut Kotler \& Armstrong (2010), adalah sebuah lokasi/distribusi yang memiliki serangkaian berlika-liku dalam proses menyediakan produk/layanan untuk siap digunakan. Karena tempat di mana produk/jasa tersebut di pasarkan, maka tempat harus memiliki prosedur berdekatan dengan lokasi pelanggan agar mudah di kunjungi, tempat juga harus strategis agar dapat dijangkau oleh pelanggan dan juga tempat harus dibuat senyaman mungkin sesuai dengan keinginan pelanggan.

\section{Promotion}

Singh (2012) mendefinisikan promosi adalah sebuah kegiatan yang dibuat oleh perusahaan dalam menginformasikan produk yang mereka ciptakan, serta untuk menarik pelanggan potensial untuk membeli. Dengan adanya kegiatan promosi, perusahaan dapat memberitahukan produk/jasa yang dijual secara cepat kepada konsumen, agar nantinya pelanggan dapat mengetahui produk yang dijual sehingga timbul rasa keinginan untuk membeli. Periklanan merupakan bagian kuat dari bauran promosi (Singh, 2012). Tujuan dari iklan itu sendiri untuk memperkenalkan produk/jasa secara luas di zona pasar serta membuat suatu citra perusahaan dari iklan yang ditampilkan.

\section{People}

Karyawan adalah pihak yang berinteraksi pada pelanggan dengan tujuan menunjukkan perhatian ,siap untuk membantu, selalu bersikap sopan, dan mampu menunjukkan perilaku yang cepat tanggap yang dapat cenderung berkontribusi signifikan untuk memperkuat hubungan pelanggan dengan karyawan (Kushwaha \& Agrawal, 2015). Maka dari itu setiap perusahaan harus mampu memiliki karyawan/SDM yang terbaik, apalagi kalau perusahaan tersebut termasuk dalam bidang jasa yang hampir setiap prosesnya dilakukan oleh karyawan/SDM dari perusahaan itu sendiri. Jadi orang yang bekerja di perusahaan tersebut harus mampu memberikan pelayanan yang maksimal, memiliki sikap yang ramah dan juga dapat membantu semua yang pelanggan inginkan serta butuhkan. Melihat saat ini di mana sumber daya manusia adalah tulang punggung industri mana pun, alih-alih keuangan, itu sebabnya personel yang bekerja pada layanan memiliki hubungan positif dan signifikan dengan loyalitas pelanggan dengan hasil yang beragam lagi tetapi bervariasi sesuai dengan satu layanan ke layanan lain (Almuhrzi \& Alsawafi, 2017; Tayebi et al., 2019).

\section{Process}

Proses di sini bertujuan memberikan pelayanan yang terbaik dan maksimal pada setiap pelanggannya ketika pertama kali menggunakan produknya, yang berfungsi agar setiap pelanggan merasa terpuaskan dengan layanan yang telah diberikan akan produk dan jasa dari perusahaan tersebut. Hashim \& Hamzah (2014) mendefinisikan proses ialah hal yang penting di dalam bauran pemasaran, karena proses kesan pertama yang dirasakan oleh pelanggan dalam proses penggambaran tentang suatu perusahaan.

\section{Physical Evidence}

Bukti fisik adalah lingkungan di mana layanan dilakukan, di lingkungan tersebut pelanggan dan perusahaan saling berinteraksi, dan di setiap unsur berwujud nantinya menghasilkan kinerja layanan (Azila-gbettor et al., 2013). Bukti fisik erat kaitannya dengan objek/penampilan yang di jumpai oleh pelanggan pertama kali di lokasi sekitar, yang nantinya menjadi bahan penilaian kualitas perusahaan tersebut. 


\section{PROPAGANDA}

\section{Loyalitas Pelanggan (Customer Loyalty)}

Ketika suatu pelanggan menggunakan produk/jasa yang ada di pasar secara berulangulang berarti pelanggan tersebut menerima kepuasan akan produk/jasa tersebut. Dampak dari kepuasan itu sendiri menjadikan pelanggan tersebut setia akan merek yang di gunakan itu yang membuat pelanggan akan loyal. Perilaku pembelian secara berulang yang dilakukan pelanggan diperkirakan sebagai syarat dasar untuk memperoleh loyalitas yang diikuti oleh kepuasan (Punniyamoorthy \& Prasanna Mohan Raj, 2007).

Menurut Kotler \& Keller (2008), kesetiaan pelanggan adalah hubungan yang sangat kuat untuk menggunakan kembali atau menjadikan produk atau layanan selalu di benak pikiran yang disukai di masa mendatang terlepas dari pengaruh situasional dan upaya pemasaran yang dapat menyebabkan perilaku pergantian produk. Dengan begitu pelanggan tidak akan lagi mengganti merek lain jika sudah setia dengan merek yang di gunakan tersebut. Berbagai cara pasti dilakukan oleh setiap perusahaan penjual produk/jasa agar setiap pelanggan nantinya mau menggunakan produknya secara terus-menerus. Seperti dalam menerapkan bauran pemasaran yang terdiri dari 7 elemen diyakini dapat mewakili strategi perusahaan, maka dari itu, percampuran dari beberapa elemen ini pada akhirnya dapat mengarah pada memperolehnya loyalitas pelanggan (Mohsan et al., 2011). Karena dengan loyal nya pelanggan akan suatu merek, maka akan memberikan keuntungan jangka panjang bagi perusahaan tersebut seperti dalam persaingan yang semakin banyak dari merek lain.

Dalam buku yang berjudul Marketing Management, (Kotler \& Keller, 2009) menyebutkan 4 indikator sebagai pengukuran loyalitas pelanggan, adalah: kemauan pelanggan untuk membagikan beberapa hal baik dari percakapan-percakapan tentang produk dan layanan, kemauan pelanggan untuk terus membeli produk / layanan tertentu, niatan pelanggan untuk memberikan masukan referensi kepada perusahaan mengenai peningkatan produk / layanan, dan juga adanya niat pelanggan dalam melakukan crossselling. Dan dalam penelitian ini hanya menggunakan 3 indikator saja kecuali indikator "niatan pelanggan untuk memberikan masukan referensi kepada perusahaan mengenai peningkatan produk / layanan" karena pada perusahaan DetailBOX sendiri tidak disediakan suatu masukan referensi/saran terkait layanan, maka dari itu indikator tersebut tidak digunakan dalam penelitian. Jika beberapa indikator tersebut dapat terlihat atau dimiliki oleh setiap pelanggan, maka hal tersebut mampu menjadikan ukuran untuk perusahaan dikatakan memiliki keloyalan di benak pelanggannya.

Roberts, K. \& Brodie (2003) juga memiliki 6 indikator di antaranya adalah membagikan informasi, memberitahukan hal-hal yang positif, merekomendasikan kepada teman, melanjutkan pembelian, membeli tambahan layanan, menguji layanan baru. Dan dari ke 6 indikator tersebut, peneliti hanya menggunakan 4 indikator kecuali pada indikator "membeli tambahan layanan dan menguji layanan baru" pasalnya 2 indikator tersebut tidak disediakan oleh DetailBOX maka dari itu tidak sesuai dengan penelitian ini.

Suatu organisasi harus mengukur tingkat strategi bauran pemasarannya, yang menimbulkan efek terhadap kepuasan pelanggan serta loyalitas pelanggan (Kofi Nyarko et al., 2016). Yang nantinya dari pengukuran itu sendiri, perusahaan dapat mengkaji dari faktor apa sajakah yang bisa membuat pelanggan loyal akan produk/jasa di pasaran.

\section{Hubungan antara Bauran Pemasaran terhadap Loyalitas Pelanggan}

Pemasaran diartikan lebih dari fungsi bisnis lainnya, mungkin definisi sederhana nya adalah dari kegiatan pemasaran, perusahaan mampu mengelola hubungan pelanggan yang saling menguntungkan. Pemasaran juga memiliki tujuan lain yaitu mengikat orang atau pelanggan baru dengan memberikan manfaat superior serta ikut mempertahankan pelanggan dan juga memanjakan pelanggan yang sudah ada dengan segala kepuasan (Kotler, 2011). Karena dari itu dari kegiatan pemasaran, perusahaan dapat memiliki pelanggan baru dengan 
berbagai cara yang perusahaan ciptakan melalui program pemasaran tersebut, dan juga dapat serta menjalin hubungan baik dengan pelanggan lamanya agar tetap bertahan akan produk/jasa yang diberikan perusahaan karena efek kepuasan yang pelanggan rasakan.

Bauran pemasaran disebut 7Ps di antaranya (product, price, place, promotion, people, process, physical evidence), yakni sebagai variabel independen, sementara pelanggan loyalitas adalah variabel dependen (Lihat Gambar 1). Elemen-elemen tersebut bertujuan untuk mengetahui hubungan di antara bauran pemasaran dengan loyalitas pelanggan.

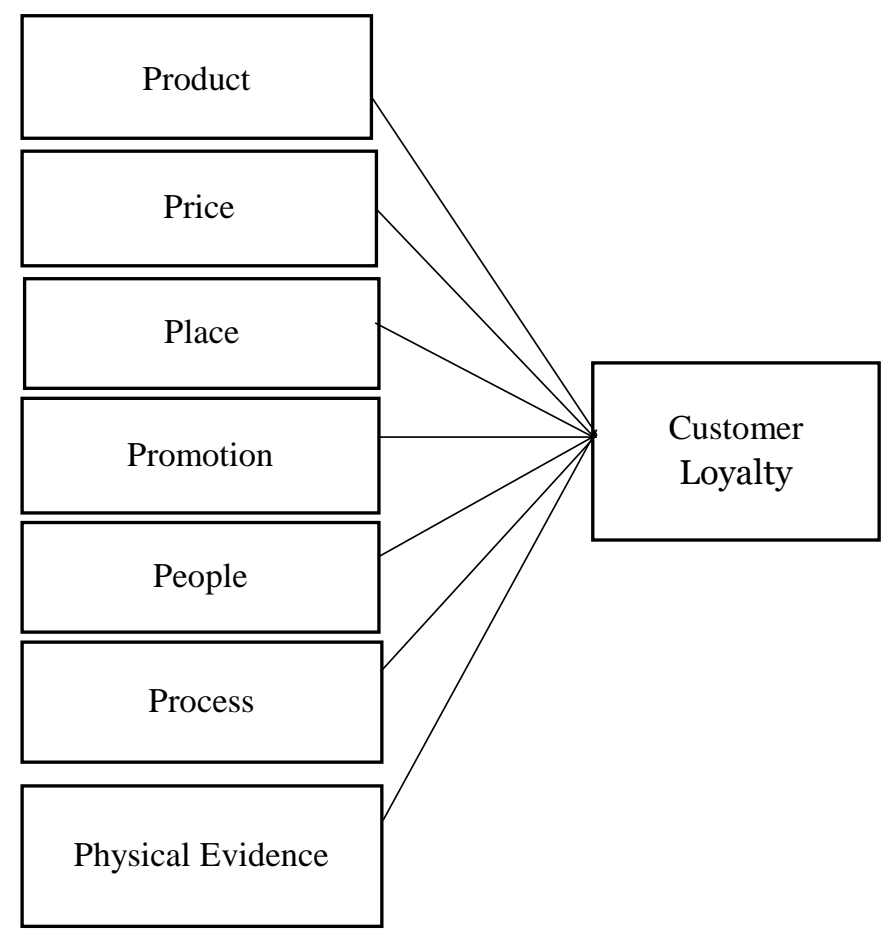

Gambar 1. Model Penelitian

H0 : Bauran Pemasaran (7Ps) secara keseluruhan tidak memiliki hubungan dengan loyalitas pelanggan di DetailBOX Autodetailing Center.

H1: Bauran Pemasaran (7Ps) secara keseluruhan memiliki hubungan dengan loyalitas pelanggan di DetailBOX Autodetailing Center.

$\mathrm{H} 2$ : Produk secara individual memiliki hubungan dengan loyalitas pelanggan di DetailBOX Autodetailing Center.

H3 : Harga secara individual memiliki hubungan dengan loyalitas pelanggan di DetailBOX Autodetailing Center.

H4 :Tempat secara individual memiliki hubungan dengan loyalitas pelanggan di DetailBOX Autodetailing Center.

H5 : Promosi secara individual memiliki hubungan dengan loyalitas pelanggan di DetailBOX Autodetailing Center.

H6 : Orang secara individual memiliki hubungan dengan loyalitas pelanggan di DetailBOX Autodetailing Center.

H7 : Proses secara individual memiliki hubungan dengan loyalitas pelanggan di DetailBOX Autodetailing Center.

H8 : Bukti Fisik secara individual memiliki hubungan dengan loyalitas pelanggan di DetailBOX Autodetailing Center. 


\section{PROPAGANDA}

\section{METODE}

Penelitian ini bertujuan untuk mengetahui hubungan bauran pemasaran dengan loyalitas pelanggan pada perusahaan DetailBOX Autodetailing Center dan dari 7 elemen bauran pemasaran, elemen apa yang paling signifikan terhadap loyalitas pelanggan.

Dalam penelitian ini menggunakan metode Kuantitatif. Adapun responden yang akan digunakan adalah pelanggan dari DetailBOX. Googleforms juga digunakan oleh peneliti dalam membagikan kuesioner kepada responden. Dalam kuesioner, menggunakan pertanyaan berskala Likert 5 poin. Dalam penelitian ini, Variabel dependen akan menjadi loyalitas pelanggan terhadap DetailBOX Autodetailing sebagai akibat dari efek Variabel independen.

Dalam pengambilan sampel, peneliti menggunakan teknik non probability sampling dengan metode Convenience Sampling. Pasalnya peneliti tidak mendapatkan akses kontak pelanggan, maka dari itu peneliti langsung mengambil data responden yang berada langsung di store DetailBOX. Kriteria sampel responden yang mengisi kuesioner tentunya pelanggan yang sudah menggunakan secara terus menerus atau di atas 2 kali menggunakan jasa DetailBOX. Adapun jumlah dalam pengambilan sampel adalah 125 ukuran sampel minimum dari (Pallant, 2005). Rumusnya adalah sebagai berikut:

Keterangan :

$$
\mathrm{n} \geq 50+8 \mathrm{~m}
$$

$\mathrm{n}=$ Jumlah Sampel

$\mathrm{m}=$ Jumlah Variabel

Setelah menghitung jumlah sampel, didapatkan hasil 114, namun peneliti mengembangkan menjadi 125 sampel karena mengantisipasi adanya data kuesioner yang tidak valid maka jumlah sampel dilebihkan. SPSS juga digunakan peneliti untuk menjalankan data statistik dan menganalisis hasil. Untuk mengolah data peneliti menggunakan regresi linier berganda untuk mengukur hubungan antara beberapa variabel independen dan variabel dependen yang bertujuan mengamati dampak bauran pemasaran terhadap loyalitas pelanggan pada DetailBOX. serta untuk menganalisis dari 7P manakah yang memiliki dampak paling signifikan terhadap loyalitas pelanggan DetailBOX.

Agar tercegah dari bias dan distorsi, keandalan dan validitas yaitu 2 konsep yang penting digunakan. Menurut Cooper \& Schindler (2014), uji validitas membuktikan sejauh mana suatu instrumen mengukur apa yang seharusnya diukur. Dari uji validitas tersebut berguna untuk memastikan bahwa data tersebut valid yang harus berada di atas nilai 0,3 (Azwar, 2014).

Uji reliabilitas juga dilakukan oleh peneliti sebagai jaminan pasalnya data tersebut dapat diandalkan, yang berguna sebagai tidak adanya kesalahan. Dan juga dalam melakukan uji reliabilitas, peneliti akan menggunakan keandalan konsistensi internal. Juga pada penggunaan skala likert dalam kuesioner, Cronbach's Alpha standarnya digunakan oleh peneliti. Seperti yang dikemukakan oleh (Ghozali I, 2016), data dikatakan reliabel dan dapat diterima standarnya yaitu bila Cronbach's Alpha memiliki nilai lebih dari 0,6.

\section{HASIL DAN PEMBAHASAN}

\section{Hasil}

Setelah peneliti membagikan kuesioner ke 125 responden DetailBOX seperti dalam penarikan jumlah sampel menurut Pallant (2005), maka didapatkan hasil seperti di bawah ini: 
Berdasarkan analisis data responden, pada Jenis Kelamin mendapatkan hasil 125 responden, untuk laki-laki memperoleh 87 responden dengan persentase $69.6 \%$, sedangkan untuk perempuan memperoleh 38 responden dengan persentase $30.4 \%$. Untuk Usia, responden terbanyak dalam penelitian ini adalah di usia 25-28 Tahun dengan 54 responden dengan persentase $43.2 \%$. Di dalam menggunakan layanan DetailBOX setiap pelanggan yang mengunjungi paling sering datang yaitu pada 2 bulan sekali dengan persentase $52.0 \%$. Adapun layanan yang paling sering digunakan adalah ceramic coating paint protection dengan persentase $55.2 \%$.

\section{Uji Validitas dan Reliabilitas}

Berdasarkan hasil dari Uji Validitas, menunjukkan bahwa bukti penelitian ini sudah valid dikarenakan menunjukkan angka diatas 0.3 pada setiap item bauran pemasaran sebagai independent variable dan setiap item loyalitas pelanggan sebagai dependent variable. Untuk nilai validitas yang paling tinggi terdapat di item indikator (process) dengan nilai .883 pada variabel bauran pemasaran, dan angka paling rendah terdapat di item indikator pada variabel loyalitas pelanggan dengan nilai .439 .

Setelah menghitung Uji Validitas, selanjutnya yaitu menghitung reliabilitas menggunakan Cronbach's Alpha. Berdasarkan hasil tabel di atas diketahui bahwa setiap item dimensi bauran pemasaran memiliki nilai di atas 0.6 dan juga untuk loyalitas pelanggan diketahui memiliki nilai di atas 0.6. Maka dari itu kedua variabel tersebut sudah reliabel. Untuk nilai reliabilitas bauran pemasaran nilai yang paling tinggi terdapat di dimensi (people) dengan nilai .666 dan nilai paling rendah terdapat di dimensi (price) dengan nilai .607.

\section{Analisis Data}

Tabel 3. Nilai Pearson Correlation Y

\begin{tabular}{lr|r|r|r|r|r|r|r|r}
\hline total Y Pearson Correlation & .198 & $-0,034$ & .228 & 0,082 & .187 & $-0,074$ & .182 & 1 \\
\hline Sig. (2-tailed) & 0,027 & 0,710 & 0,011 & 0,365 & 0,037 & 0,413 & 0,043 & \\
\hline N & 125 & 125 & 125 & 125 & 125 & 125 & 125 & 125 \\
\hline
\end{tabular}

Tabel 4. Nilai Signifikasi Bauxan Pemasaxan

\begin{tabular}{|l|l|}
\hline & Sig. (2-tailed) \\
\hline totalproduct & 0,027 \\
\hline totalerice & 0,710 \\
\hline totalplace & 0,011 \\
\hline totaleremetion & 0,365 \\
\hline totaldeedple & 0,037 \\
\hline totalprecess & 0,413 \\
\hline totalphyevi & 0,043 \\
\hline
\end{tabular}

Hasil pada tabel 4. Di atas tersebut menunjukkan bahwa beberapa dimensi bauran pemasaran memiliki suatu hubungan dengan loyalitas pelanggan. Itu terlihat dari beberapa nilai dimensi bauran pemasaran yang memiliki nilai sig. Di bawah 0,05 meliputi dimensi (produk, tempat, orang dan bukti fisik). Artinya hasil hipotesis 0 diterima karena secara keseluruhan dimensi bauran pemasaran tidak memiliki hubungan dengan loyalitas pelanggan, sedangkan beberapa hipotesis lainnya diterima bahwa hanya beberapa saja dimensi bauran pemasaran yang memiliki hubungan dengan loyalitas pelanggan di antaranya produk, tempat, orang dan 


\section{PROPAGANDA}

bukti fisik, sementara dimensi bauran pemasaran yang lainnya ditolak karena tidak memiliki hubungan dengan loyalitas pelanggan.

Dengan ini sesuai dari beberapa penelitian yang di antaranya dilakukan oleh (Tjan, 2015) dalam meneliti pelanggan di pusat perbelanjaan, bahwa hasilnya beberapa dimensi bauran pemasaran memiliki hubungan dengan loyalitas pelanggan seperti produk, lokasi, promosi dan bukti fisik. Dan juga penelitian yang dilakukan oleh (Owomoyela et al., 2013) untuk sebuah pabrik di Nigeria yang merekomendasikan pada keunggulan setiap produk yang dibuat, memberikan harga yang mampu berkompetitif dengan produk pesaing, tempat yang strategis, melakukan promosi ke segala arah dan memberikan manfaat yang tepat kepada konsumen.

Adapun perbedaan dari beberapa jurnal rujukan sebelumnya dengan penelitian ini seperti dalam penelitian yang dilakukan oleh Tjan (2015) di suatu mal perbelanjaan Jakarta, terkait dengan beberapa indikator loyalitas pelanggan di mana dalam penelitian tersebut menggunakan indikator terkait "layanan tambahan" yang di mana dalam penelitian DetailBOX ini tidak digunakan karena tidak sesuai dengan objek penelitian ini terkait dengan seputar otomotif kendaraan yang berbeda dengan pusat perbelanjaan.

\section{Uji Hubungan Antar Variabel}

\section{Tabel 5. Analisis Pearson Correlations X Dan Y}

\begin{tabular}{llr|r} 
& & total X & \multicolumn{1}{c}{ total $\mathrm{Y}$} \\
\hline total X & Pearson Correlation & 1 & .134 \\
\cline { 2 - 4 } & Sig. (2-tailed) & 125 & .138 \\
\cline { 2 - 4 } & $\mathrm{N}$ & .134 & 125 \\
\hline total $\mathrm{Y}$ & Pearson Correlation & .138 & \\
\cline { 2 - 4 } & Sig. (2-tailed) & 125 & 125 \\
\cline { 2 - 4 } & $\mathrm{N}$ & & \\
\hline
\end{tabular}

Tahap selanjutnya adalah menguji hubungan kedua variabel bauran pemasaran dengan loyalitas pelanggan, dalam mengetahui apakah adanya hubungan bauran pemasaran dengan loyalitas pelanggan di perusahaan DetailBOX, peneliti sudah menganalisis secara keseluruhan hubungan variabel $\mathrm{X}$ dengan Variabel Y dengan pengukuran Correlations. bahwa hasilnya pada tabel di atas adalah variabel bauran pemasaran dengan loyalitas pelanggan tidak memiliki hubungan terbukti dengan tabel 5. analisis Pearson Correlation X dan Y dengan nilai .134 yang di mana nilai hubungan antar kedua variabel rendah.

\section{Pembahasan}

Karena hasil analisis hubungan variabel $\mathrm{X}$ dengan Variabel $\mathrm{Y}$ terbukti tidak memiliki hubungan yang kuat, maka peneliti menghitung kembali hubungan setiap dimensi bauran pemasaran dengan loyalitas pelanggan dengan pengukuran yang sama yaitu menggunakan Correlations guna melihat hasil hipotesis. Berdasarkan hasil analisis di atas didapatkan hasil hipotesis dari 7 dimensi bauran pemasaran, hanya ada 4 dimensi yang berpengaruh terhadap loyalitas pelanggan yaitu pada (produk, tempat, orang, dan bukti fisik). Ke-4 dimensi tersebut mengisyaratkan saling berhubungan seperti dalam produk, karena banyaknya jenis produk coating yang dijual oleh DetailBOX untuk body kendaraan sampai dengan cleaning engine, menjual aksesoris pada kendaraan seperti Velg, Sparepart dan yang lainnya. Tempat, karena DetailBOX berada pada area yang strategis dijangkau setiap pelanggannya yang terletak di ibu kota Jakarta, dekat dengan akses kendaraan umum dan juga tempatnya menyediakan beberapa fasilitas seperti Coffee Shop, Car Service yang di sediakan untuk pelanggan. Orang, di mana 
setiap pegawai atau pekerja di DetailBOX mampu bekerja dengan baik, sopan melayani pelanggan serta mampu menjelaskan segala informasi tentang produk dan layanan. Dan bukti fisik, di sini terlihat karena bukti tempat di mana DetailBOX melakukan kegiatan jasa nya mengedepankan kenyamanan, seperti menggunakan pencahayaan yang maksimal, desain tempat yang di sesuaikan dengan selera penikmat otomotif.

\section{PENUTUP}

Dari hasil penelitian ini, dapat diambil kesimpulan bahwa Bauran Pemasaran (X) tidak memiliki hubungan yang kuat terhadap Loyalitas Pelanggan (Y) di perusahaan jasa DetailBOX Autodetailing Center itu terbukti dari analisis Pearson Correlation X dan Y dengan nilai .134 yang di mana nilai hubungan antar kedua variabel rendah. Meskipun dari beberapa dimensi ada yang memiliki hubungan, terbukti dari hasil nilai beberapa dimensi bauran pemasaran yang memiliki nilai sig. Di bawah 0,05. Terletak pada (produk) dengan nilai 0,027, (tempat) dengan nilai 0,011, (orang) dengan nilai 0,037 dan (bukti fisik) dengan nilai 0,043. Adapun saran dari peneliti untuk perusahaan seperti dalam beberapa dimensi yang tidak berhubungan meliputi (harga), dari segi harga agar lebih di sesuaikan lagi yang nantinya lebih terjangkau atau melakukan riset tentang harga per produk yang dijual. (Promosi), karena dari segi promosi hanya dilakukan melalui beberapa media sosial, agar ke depannya lebih dikembangkan kembali agar promosi nya semakin luas ke pelanggan. Dan pada dimensi (proses), karena proses langsung berhubungan dengan kinerja pekerjaan, agar setiap prosedur tahap pekerjaan lebih di maksimalkan. Dan pastinya harus terus melakukan inovasi terhadap produk dan layanan yang dijual guna memberikan kepuasan maksimal kepada pelanggan yang nantinya akan berujung pada loyal nya pelanggan menggunakan produk serta layanan tersebut.

\section{DAFTAR PUSTAKA}

Almuhrzi, H. M., \& Alsawafi, A. M. (2017). Muslim perspectives on spiritual and religious travel beyond Hajj: Toward understanding motivations for Umrah travel in Oman. Tourism Management Perspectives, 24, 235-242. https://doi.org/10.1016/j.tmp.2017.07.016

Azila-gbettor, E. M., Avorga, S. M. K., Danku, L. S., \& Atatsi, E. A. (2013). Physical Evidence and Quality Service Delivery in Public Hospitals in Ghana. International Review of Management and Marketing, 3(4), 153-163.

Azwar, S. (2014). Reliabilitas dan Validitas: Interpretasi dan Komputasi. Yogyakarta: Pustaka Pelajar.

Cooper, D. R., \& Schindler, P. S. (2014). Business Research Methods (Vol. 12). New York City, New York, United States of America: McGraw-Hill.

Daryanto. (2011). Sari kuliah manajemen pemasaran. PT Sarana Tutorial Nurani Sejahtera. DetailBOX. (2015). DetailBOX. 2015. https://DetailBOX.id/about/

Friesner, T. (2014). Marketing Teacher. Retrieved from Marketing Teacher. 2 Mei.

Ghozali I. (2016). Aplikasi Analisis Multivariete Dengan Program IBM SPSS 23 ((8th ed.)). Badan Penerbit Universitas Diponegoro.

Hashim, N., \& Hamzah, M. I. (2014). 7P's: A Literature Review of Islamic Marketing and Contemporary Marketing Mix. Procedia - Social and Behavioral Sciences, 130, 155-159. https://doi.org/10.1016/j.sbspro.2014.04.019

Hurriyati, R. (2010). Marketing Mix and Consumer Loyalty. bandung alfabeta.

Ibomendel, M. (2008). Actual practices of marketing mix and its impact on customer loyalty. 


\section{PROPAGANDA}

Gaza, Palestine.

Khan, S. M., \& Mahmood, R. (2014). Impact of Service Marketing Mixes on Customer Perception: A Study on Eastern Bank Limited, Bangladesh. European Journal of Business and Management, 164-172.

Kofi Nyarko, I., Agyeman-Duah, M. O., \& Asimah, V. (2016). Measuring Customer Loyalty Using Retention, Advocacy and Patronage as Key Denominators. International Journal of Scientific and Research Publications, 6(2), 375-380. www.ijsrp.org

Kotler, P. (2011). Marketing Management, Millenium Edition. Prentice-Hall of India.

Kotler, P., \& Armstrong, G. (2010). Principles of marketing. Pearson education.

Kotler, P., \& Keller, K. L. (2008). Marketing Management 13th Edition. Prentice Hall.

Kotler, P., \& Keller, K. L. (2009). Marketing Management (Vol. 6). Pearson Prentice Hall.

Kushwaha, G. S., \& Agrawal, S. R. (2015). An Indian customer surrounding 7P[U+05F3]s of service marketing. Journal of Retailing and Consumer Services, 22, 85-95. https://doi.org/10.1016/j.jretconser.2014.10.006

Mohsan, F., Nawaz, M. M., Khan, M. S., Shaukat, Z., \& Aslam, N. (2011). Impact of customer satisfaction on customer loyalty and intentions to switch: evidence from banking sector of Pakistan. International Journal of Business and Social Science, 2(16), 263-270.

Othman, B. A., \& Harun, A. Bin. (2018). Issues and Challenges Faced by Malaysian Umrah Travel Agencies in Providing Excellent Marketing Mix Services to Umrah Pilgrims. The Journal of Social Sciences Research, SPI 2, 611-618. https://doi.org/10.32861/jssr.spi12.611.618

Owomoyela, S., Ola, O., \& Oyeniyi, K. (2013). Investigating the impact of marketing mix elements on consumer loyalty: An empirical study on Nigerian Breweries PLC. Interdisciplinary Business Research, 4(11), 485-496.

Pallant, J. (2005). SPSS survival manual : a step by step guide to data analysis using SPSS for Windows (Version 12). Crows Nest, NSW, Australia: Allen \& Unwin, 2005. https://www.worldcat.org/title/spss-survival-manual-a-step-by-step-guide-to-dataanalysis-using-spss-for-windows-version-12/oclc/60638932

Punniyamoorthy, M., \& Prasanna Mohan Raj, M. (2007). An empirical model for brand loyalty measurement. Journal of Targeting, Measurement and Analysis for Marketing, 15(4), 222-233. https://doi.org/10.1057/palgrave.jt.5750044

Rahadiansyah, R. (2020). Macet di Mana-mana, Berapa Jumlah Mobil di Indonesia? Ini Datanya. 23 Januari. https://oto.detik.com/mobil/d-4870190/macet-di-mana-manaberapa-jumlah-mobil-di-indonesia-ini-datanya

Roberts, K., S. V., \& Brodie, R. (2003). Measuring the quality of relationship in consumer services: an empirical study. European Journal of Marketing, 37, 169-196.

Singh, M. (2012). Marketing Mix of 4P'S for Competitive Advantage. IOSR Journal of Business and Management, 3(6), 40-45. https://doi.org/10.9790/487x-0364045

Tayebi, S. M., Manesh, S. R., Khalili, M., \& Sadi-Nezhad, S. (2019). The role of information systems in communication through social media. International Journal of Data and Network Science, 3(3), 245-268. https://doi.org/10.5267/j.ijdns.2019.2.002

Tjan, S. (2015). The Impact of Marketing Mix On Customer Loyalty Towards Plaza Indonesia Shopping Center. IBuss Management, 3(2), 392-402. https://media.neliti.com/media/publications/184720-EN-the-impact-of-marketing-mixon-customer.pdf

Widowati, H. (2019). Berapa Jumlah Kendaraan di DKI Jakarta? 2 Agustus. https://databoks.katadata.co.id/datapublish/2019/08/02/berapa-jumlah-kendaraan-di-dkijakarta 